\section{Analysis of L-Dopa in Human Serum}

BioTechniques 33:1000-1002 (November 2002)

Among the drugs acting on the dopaminergic system, L-dopa is the most important one for treatment of patients with Parkinson's disease (2). The monitoring of L-dopa concentrations in plasma has clarified and solved several pharmacokinetic problems, such as recognizing pharmacokinetic interactions and producing new types of preparations such as controlled release drugs (2).

Sagar and Smyth (3) recently published an advanced column-switching method for the analysis of L-dopa and referenced 18 methods from 19621986, but not more modern and simpler methods. In studies of the pharmacokinetics of the drug (1), we used an HPLC method combined with a simple clean-up procedure employing the properties of boronate gel to capture chemical compounds that, similar to Ldopa, contain vicinal hydroxyls. After washing the sample adsorbed to the gel, L-dopa was eluted in a weakly acidic solution and subjected to HPLC. However, the boronate affinity gel PBA-30 (Amicon, Danvers, MA, USA) we used disappeared from the market, and in search for a substitute, we found a similar preparation, Prosep ${ }^{\circledR}$-PBA (Millipore, Consett, Durham, UK), which was suitable for our purposes. We also investigated the boronate binding of $\alpha$ methyldopa as a promising internal standard candidate.

We used L-dopa from Merck (Darmstadt, Germany) and $\alpha$-methyldopa from Sigma (St. Louis, MO, USA). We prepared $1 \mathrm{~mL}$ boronate gel in Econocolumns $(0.7 \times 4.0 \mathrm{~cm}$; Bio-Rad Laboratories, Hercules, CA, USA) by equilibrating the gel with $25 \mathrm{~mL} 100 \mathrm{mM}$ phosphate buffer, $\mathrm{pH} 8.3$, containing 2.7 $\mathrm{mM}$ EDTA and $5.3 \mathrm{mM}$ sodium metabisulphite. The columns could be re-equilibrated and reused several times.

Stock solutions of L-dopa and DL- $\alpha$ methyldopa (both $10 \mathrm{mM}$ ) were prepared in an aqueous solution of $10 \mathrm{mM}$ hydrochloric acid and $0.2 \mathrm{mM}$ EDTA. These solutions were freshly prepared on the day of analysis. We prepared a working standard solution by diluting L- dopa and $\alpha$-methyldopa to $2.0 \mu \mathrm{M}$ with mobile phase $(0.1 \mathrm{mM}$ formic acid, 0.2 mM EDTA, pH 3.1) and made solutions with varying concentrations of the calibrator and internal standard for experimental studies. The $\alpha$-methyldopa was diluted to $100 \mu \mathrm{M}$ with the hydrochloric acid-EDTA solution and added to the samples as an internal standard.

For the analysis of L-dopa, we added $1.3 \mathrm{~mL}$ serum sample to analytical tubes. Then $26 \mu \mathrm{L} 100 \mu \mathrm{M} \alpha$-methyldopa were added, the samples were thoroughly mixed, and $35 \mu \mathrm{M}$ EDTA were added and mixed. For protein precipitation, $200 \mu \mathrm{L} 4 \mathrm{M} \mathrm{HClO}_{4}$ were added, samples centrifuged at $3000 \times g$ at $4^{\circ} \mathrm{C}$ for $10 \mathrm{~min}, 1.1-\mathrm{mL}$ aliquots of the supernatants were added to new tubes containing $1.3 \mathrm{~mL} 1 \mathrm{M} \mathrm{K}_{2} \mathrm{HPO}_{4}$, and the samples were thoroughly mixed. The samples were centrifuged at $3000 \times g$ at $4^{\circ} \mathrm{C}$ for $10 \mathrm{~min}$, and $2.2 \mathrm{~mL}$ of the supernatants were transferred to the equilibrated Prosep-PBA boronate columns. The column was washed with $1.5 \mathrm{~mL} 100 \mathrm{mM}$ phosphate buffer, $\mathrm{pH}$ 8.3, containing $2.7 \mathrm{mM}$ EDTA and 5.3 $\mathrm{mM}$ sodium metabisulphite. For elution of L-dopa and $\alpha$-methyldopa, $0.75 \mathrm{~mL}$ $100 \mathrm{mM}$ phosphate buffer, $\mathrm{pH} 2.3$, and $0.2 \mathrm{mM}$ EDTA were added. This fraction was discarded. Then, $1 \mathrm{~mL}$ of the same acid buffer was added, and the fraction was collected in plastic vials for analysis by HPLC. The sample injection volume was $20 \mu \mathrm{L}$.

The equipment used was a model 590 HPLC pump from Waters (Milford, MA, USA), an automatic sample injector model $231 \mathrm{XL}$ from Gilson (Middleton, WI, USA), and an electrochemical detector model 460 from Waters. A model 740 data module (Waters) was used for integration and calculations.

The analytical column was a Supelcosil $\mathrm{C}_{18}$ column $(250 \times 4.6 \mathrm{~mm}$ i.d., particle size $5 \mu \mathrm{m}$ ) from Supelco (Bellefonte, PA, USA). The temperature was maintained at $30^{\circ} \mathrm{C}$ by a Temperature Control Module thermostat and column heater (Waters).

The mobile phase was a solution of $0.1 \mathrm{mM}$ formic acid and $0.2 \mathrm{mM}$ EDTA with $\mathrm{pH}$ adjusted to 3.1 with sodium hydroxide. The solution was filtered through a $0.45-\mu \mathrm{m}$ cellulose acetate filter (Sartorius, Göttingen, Germany).

Venous blood samples were ob- tained from Parkinson's patients on treatment with L-dopa. Blood samples were collected in $10-\mathrm{mL}$ vacuum tubes without additives (Becton Dickinson). After coagulation, the samples were centrifuged at $3000 \times g$ at $4^{\circ} \mathrm{C}$ for 10 min within $4 \mathrm{~h}$ of collection. Serum was then stored at $-70^{\circ} \mathrm{C}$ until analysis.

The L-dopa and $\alpha$-methyldopa peaks were well separated on the chromatogram with retention times of 7.8 and $15.4 \mathrm{~min}$, respectively. The detector responses were linear over the range of $0-10 \mu \mathrm{M}$ for both substances. When the serum samples were analyzed, an unknown peak appeared at $9.3 \mathrm{~min}$. This peak was also well separated from $\mathrm{L}$-dopa.

We investigated the optimal equilibration $\mathrm{pH}$ for the Prosep-PBA column before loading the sample. The sample was prepared from serum spiked with both L-dopa and $\alpha$-methyldopa. Very

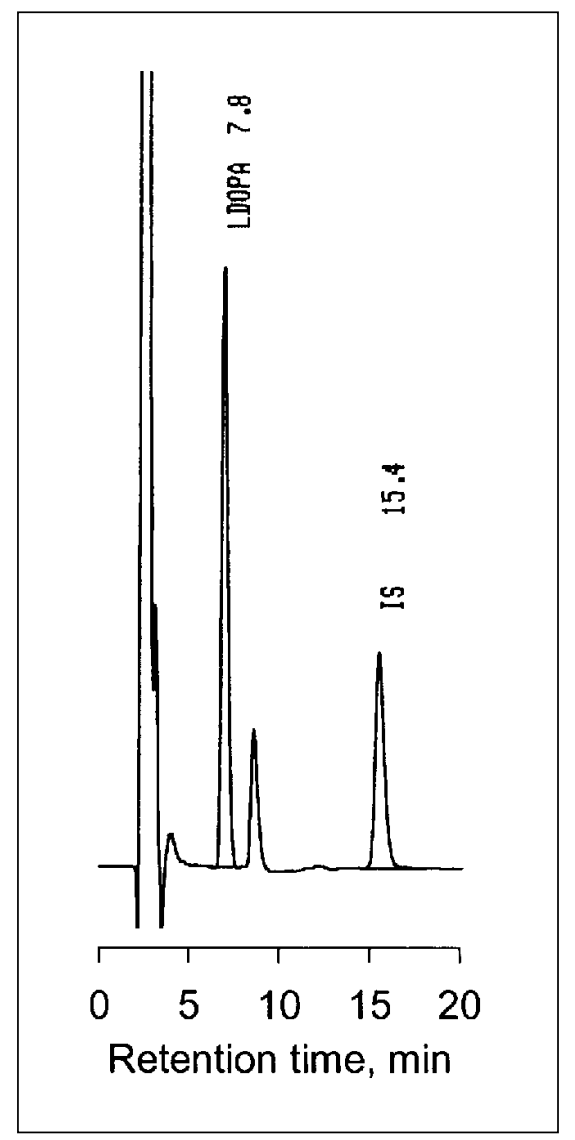

Figure 1. Chromatogram of serum L-dopa from a patient with Parkinson's disease. After continuous intravenous infusion of $85 \mathrm{mg} \mathrm{L}$ $\mathrm{dopa} / \mathrm{h}$ into the patient, a sample was obtained from the contralateral arm. The concentration of L-dopa was $3.26 \mu \mathrm{M}$. 
Table 1. Results of Duplicate Analyses of 23 Samples Obtained from Patients with Parkinson's Disease on L-Dopa Therapy

\begin{tabular}{|cccc|}
\hline $\begin{array}{c}\text { Number of } \\
\text { Samples }(\boldsymbol{n})\end{array}$ & Range $(\mu \mathrm{M})$ & $\overline{\mathbf{x}} \pm \mathrm{SD}^{\mathrm{a}}(\mu \mathrm{M})$ & $\mathrm{cv}(\%)$ \\
\hline 6 & $0-0.2$ & $0.072 \pm 0.010$ & 14 \\
8 & $0.2-4.0$ & $1.98 \pm 0.038$ & 1.9 \\
9 & $4.0-9.0$ & $6.13 \pm 0.058$ & 0.95 \\
& \\
Results were stratified into groups with low, medium, and high values. & aCalculat- \\
ed within each group from the squared difference between duplicates.
\end{tabular}

small amounts $(<10 \%)$ of L-dopa or $\alpha$ methyldopa were found in the first $0.75-\mathrm{mL}$ wash, but the next $1-\mathrm{mL}$ fraction was purified from the peak with a retention time of $9.3 \mathrm{~min}$ and contained the majority of L-dopa and $\alpha$-methyldopa. With the columns pre-equilibrated at $\mathrm{pH} 8.0-8.6$, the recoveries in this fraction were $79.3 \%-80.4 \%$ for L-dopa and $78.5 \%-79.6 \%$ for $\alpha$-methyldopa (see below for calculation). The mean difference in recoveries between the compounds was $1 \%$. We chose to preequilibrate the columns at $\mathrm{pH} 8.3$, which was slightly higher than was used earlier ( $\mathrm{pH}$ 8.0) with the boronate affinity gel PBA-30 (1).

From control serum, we prepared a pool containing $2.0 \mu \mathrm{M}$ L-dopa and 2.0 $\mu \mathrm{M} \alpha$-methyldopa. Five replicates of this pool were used for protein precipitation and further purification on the boronate column. The concentration of L-dopa found in the eluate was $1.19 \pm$ $0.03 \mu \mathrm{M}$ (CV 2.5\%), and the $\alpha$-methyldopa concentration was $1.24 \pm 0.07 \mu \mathrm{M}$ (CV 2.9\%), as calculated using the respective standard curves. Theoretically, according to the volume changes in the precipitation steps, $58 \%$ of the original sample was transferred to the column (e.g., $0.58 \times 1.3 \times 2 \mathrm{nmol}=1.51 \mathrm{nmol}$ ). At $100 \%$ recovery across the boronate purification step, an eluate concentration of $1.51 \mu \mathrm{M}$ should thus be expected. This means that the absolute recoveries across the boronate columns were $79 \%$ and $82 \%$ or better for L-dopa and $\alpha$-methyldopa, respectively. The quotient between the compounds in the five eluates was $0.94 \pm 0.013 \mu \mathrm{M}(\mathrm{CV}$ $1.4 \%)$. Thus, it seems that the recovery and the imprecision of the method were very satisfactory and the imprecision was even better if $\alpha$-methyldopa was used as an internal standard.

Table 1 shows the imprecision of the method as calculated from samples analyzed in duplicate using $\alpha$-methyldopa as internal standard. At therapeutic Ldopa concentrations, the $\mathrm{CV}$ was less than $2 \%$. From the samples with very low values, the detection limit of the method could be calculated. A detection limit of $0.03 \mu \mathrm{M}$ was obtained using three standard deviations as the definition of detection limit. This is as good as the data given by Sagar and Smyth (3) using a complicated columnswitching technique and EC detection.

The technician's time for pre-purification of one sample is $1 \mathrm{~h}$, and 20 samples can be processed within $4 \mathrm{~h}$. The chromatographic time is 20 $\mathrm{min} /$ injection. The costs of the ProsepPBA gel is $\$ 10 /$ sample, and we have regenerated the Prosep-PBA columns for reuse five times without problems. This reduces the costs further. The other reagents are very inexpensive. Thus, we think that this method is cost-effective. One may argue that the protein precipitation step might be possible to eliminate. Therefore, we tried to omit this step by only adjusting the sample $\mathrm{pH}$ to 8.3 before loading to the Prosep-PBA column. However, most proteins were retained on the boronate column and eluted together with the L-dopa. Therefore, the initial protein precipitation step seems necessary.

In extensive pharmacokinetic studies, many samples are collected and the amount of blood taken for analysis should be kept low. In this situation, the method can easily be scaled down to, for example, $0.5 \mathrm{~mL}$ serum or less, since the analytical sensitivity is so high. Still, lesser amounts of serum can be used because we only used $2 \%$ of the eluate from the boronate step for HPLC, and the injection volume therefore can be increased.

\section{REFERENCES}

1.Dizdar, N., A. Kullman, B. Norlander, J-E. Olsson, and B. Kågedal. 1999. Human pharmacokinetics of L-3,4-dihydroxyphenylalanine studied with microdialysis. Clin. Chem. 45:1813-1820.

2.Furlanut, M., M. Furnanut, Jr., and P. Benetello. 2001. Monitoring of L-dopa concentrations in Parkinson's disease. Pharmacol. Res. 43:423-427.

3.Sagar, K.A. and M.R. Smyth. 2000. Simultaneous determination of levodopa, carbidopa and their metabolites in human plasma and urine samples using LC-ED. J. Pharm. Biomed. Anal. 22:613-624.

This study was supported by grants from the Swedish Cancer Society (Project 2357B01-16XAA), the Research Foundation of the County Council of Östergötland, and the Research Foundation of Neurologiskt Handikappades Riksförbund. Address correspondence to Dr. Bertil Kågedal, Department of Biomedicine and Surgery, Division of Clinical Chemistry, University Hospital, S-581 85 Linköping, Sweden. e-mail: bertil.kagedal@lio.se

Received 14 June 2002; accepted 8 August 2002.

Nil Dizdar, Kerstin Årstrand, and Bertil Kågedal University Hospital Linköping, Sweden

For reprints of this or
any other article, contact
Reprints@BioTechniques.com

